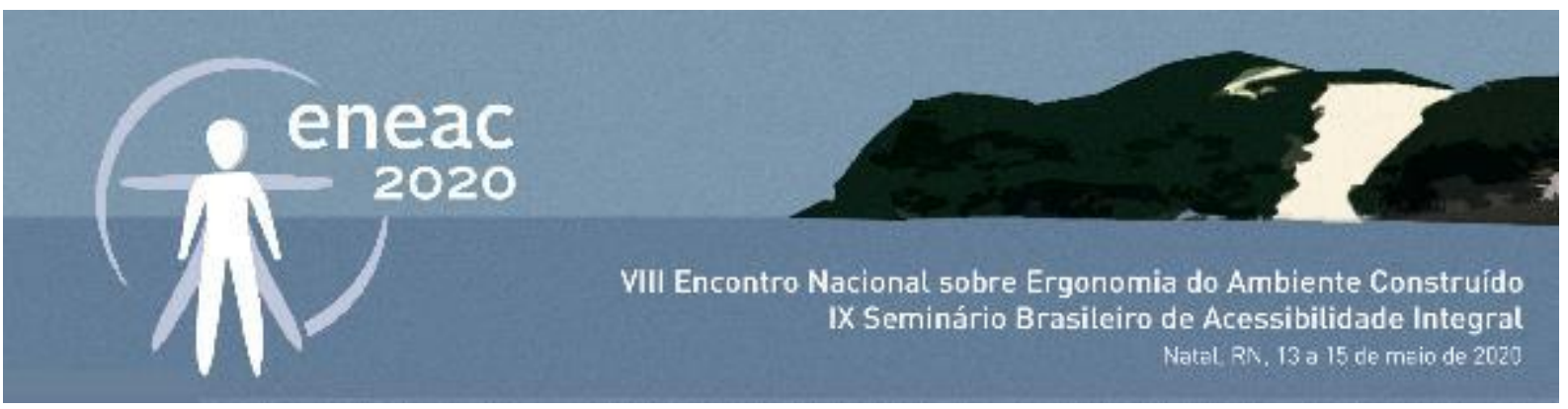

\title{
Desenvolvimento de dispositivos eletrônicos de baixo custo para pessoas surdas
}

\section{Development of low cost electronic devices for deaf people}

\author{
RAFAELLA CANEZ DE PINHO \\ Bacharel em Engenharia de Controle e Automação, Universidade Federal de Pelotas, \\ raffaelacpinho@gmail.com \\ MAYARA ZANCHIN \\ Mestre em Ciências, Universidade Federal de Pelotas, maayfrizzo@gmail.com \\ ITALO RODEGHIERO NETO \\ Doutorando em Engenharia de Produção, Universidade Federal do Rio Grande do Sul, \\ italorneto@gmail.com \\ ISABELA FERNANDES ANDRADE \\ Doutora em Arquitetura e Urbanismo, Universidade Federal de Pelotas, acessiarq@gmail.com \\ DENIS TEIXEIRA FRANCO \\ Doutor em Ciência da Computação, Universidade Federal de Pelotas, \\ denis.franco@ufpel.edu.br
}

\section{RESUMO}

A promoção da acessibilidade é uma questão importante em relação à qualidade de vida das pessoas com deficiências. A partir da pesquisa bibliográfica realizada, identificou-se que a acessibilidade para os surdos é um tópico pouco abordado, com pouquíssimos estudos na área, sendo escassos os produtos existentes para tornar a vida desses indivíduos mais acessível. A lei que implementa a acessibilidade no Brasil incentiva a busca de alternativas que visem atender à necessidade das pessoas com deficiência, dentre elas a auditiva, bem como auxiliar nas tarefas diárias dessas pessoas. Para isso, pensou-se na automação residencial, pois ela traz conforto, autonomia e segurança para as pessoas em suas casas. Dessa forma, no presente trabalho, foram desenvolvidos dois protótipos de tecnologia assistiva para deficientes auditivos. O primeiro, uma campainha eletrônica residencial que, quando acionada, envia mensagens para o celular da pessoa surda. O segundo, em formato de uma babá eletrônica, que capta o som no quarto do bebê e envia mensagens para o celular dos pais surdos, que são alertados pela vibração deste aparelho. Os resultados obtidos foram satisfatórios, atendendo às necessidades do projeto, pois é proporcionado por soluções de baixo custo e leva conforto, segurança e autonomia aos usuários com deficiência auditiva. 


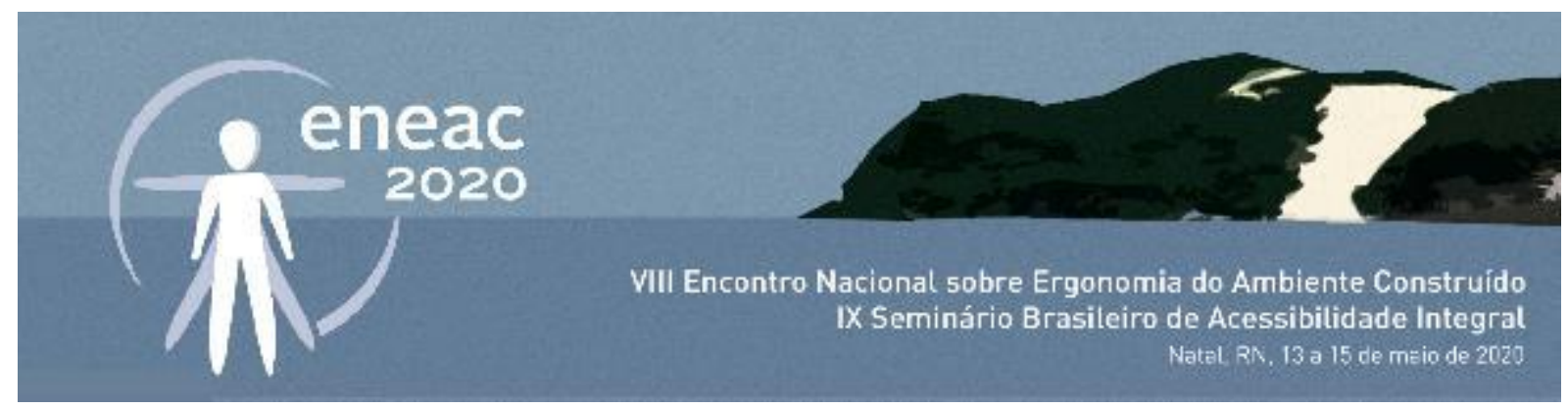

PALAVRAS-CHAVE: Acessibilidade, tecnologia assistiva, pessoas surdas, automação residencial

\begin{abstract}
The promotion of accessibility is an important issues regarding the quality of life of people with disabilities. From the research in the related literature it has been identified that accessibility for the deaf is a topic rarely addressed, with very few studies in the area, and that there are scarce existing products to make the lives of these individuals more accessible. The law that implements accessibility in Brazil states search for alternatives of how automation could assist the daily tasks of deaf people, since automation has been providing mechanisms that make life easier for people. For this, we thought about residential automation, because it brings comfort, autonomy and security to the people in their homes. This way, two prototypes of assistive technology for deaf people were developed. The first one, a residential electronic doorbell that, when triggered, sends messages to the cell phone of the deaf person. The second one, in the form of an electronic monitor, who acquires the sound in the baby's room, sends messages to the cell phone of the deaf parents, who are alerted by the vibration of this device. The results obtained were satisfactory, meeting the needs of the project, providing low cost solutions and bringing comfort, safety and autonomy to deaf users.
\end{abstract}

KEYWORDS: Accessibility, assistive technology, deaf people, home automation

\title{
1 INTRODUÇÃO
}

Conforme dados extraídos do último Censo no Brasil, realizado pelo Instituto Brasileiro de Geografia e Estatística (IBGE, 2010), cerca de 45 milhões de brasileiros possuem algum tipo de deficiência. Destes, aproximadamente 8\% são totalmente surdos. De acordo com o Decreto no 5.296 (2004), a deficiência auditiva é caracterizada pela "perda bilateral, parcial ou total de quarenta e um decibéis ( $\mathrm{dB}$ ) ou mais, aferida por audiograma nas frequências de $500 \mathrm{~Hz}, 1.000 \mathrm{~Hz}, 2.000 \mathrm{~Hz}$ e $3.000 \mathrm{~Hz}$.".

Historicamente, as pessoas com deficiência auditiva eram escondidas por suas famílias, devido as suas limitações (MOORES, 1978). Com o passar do tempo e, após a criação da Língua Brasileira de Sinais (LIBRAS), a comunicação entre as famílias começou a se desenvolver. Entretanto, o entendimento entre as famílias ainda era complexo, pois a comunicação ainda era deficitária (MONTEIRO, 2006). Somente após a regulamentação da Lei no 10.436 (2002), que dispõe sobre os direitos dos surdos, foi que este meio de comunicação e expressão foi regulamentada e padronizada.

Uma das questões mais importantes em relação à qualidade de vida de pessoas com deficiência é a acessibilidade. Conforme Andrade (2016), esta ciência pode ser entendida como a possibilidade de realizar atividades, em qualquer ambiente, visando o conforto, segurança e autonomia do indivíduo. Acessibilidade, conforme citado por Castro et al. (2010), também pode envolver as possibilidades de deslocamento do indivíduo ao longo de um ambiente físico com adequada segurança, autonomia e conforto. Dentre as dificuldades encontradas por uma pessoa com deficiência auditiva está a grande dificuldade de se comunicar com outras pessoas, como para ser atendida em instituições públicas e privadas por falta de equipamentos que poderiam tornar essa comunicação mais acessível.

A partir disto, podemos verificar que a acessibilidade está ligada diretamente à inclusão, pois ao se conceber espaços e produtos acessíveis, torna-se possível o processo de inclusão destas pessoas a 


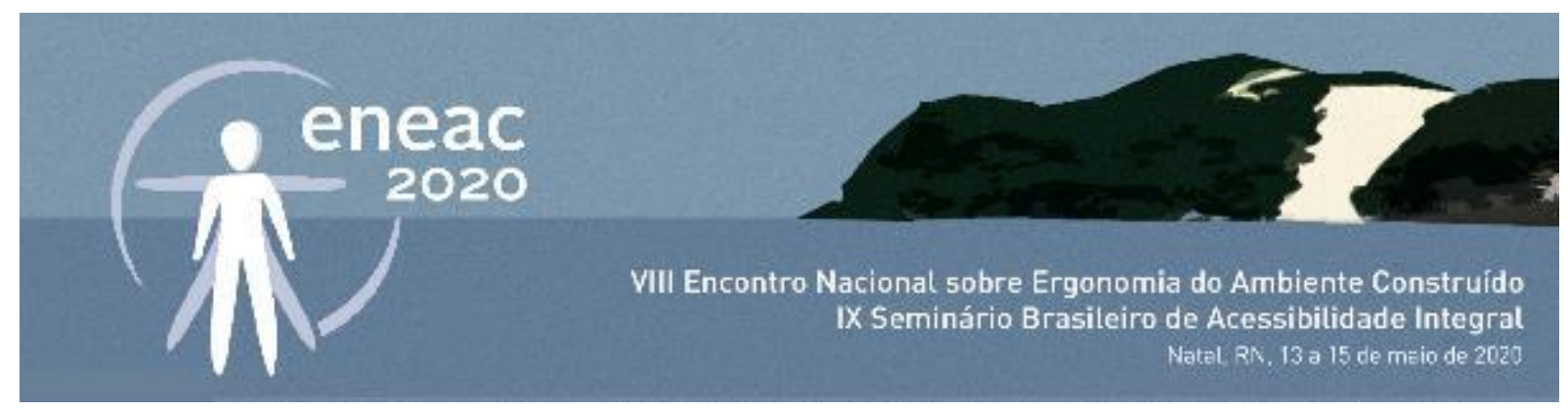

estes espaços. Dischinger et al. (2012) concordam com o tema ao afirmarem que "[...] o conceito de inclusão se refere à possibilidade de participação social em condições de igualdade e sem discriminação".

Lopez et al. (2016) afirmam que, quando se pensa em produtos que proporcionam uma vida mais acessível para as pessoas com deficiência auditiva, inicialmente são propostos produtos como aparelhos auditivos. Porém, é interessante pensar em produtos que os auxiliem no desenvolvimento de atividades sem alterar a realidade em que estão inseridos. Logo, deve-se investir em criação de equipamentos que substituam o som, para os sentidos da visão ou tato, trazendo acessibilidade ao surdo sem tentar mudar a realidade deste.

Quando se estuda sobre equipamentos que proporcionem melhores condições de acessibilidade às pessoas com deficiência ou mobilidade reduzida, é inevitável chegar ao conceito de Tecnologia Assistiva (TA). Este tipo de tecnologia traz todos os conceitos relacionados à pesquisa, fabricação, uso de equipamentos, recursos ou estratégias utilizadas para potencializar as habilidades funcionais das pessoas com deficiência. Conforme Bersch (2013), a tecnologia assistiva compreende recursos que auxiliam ou ampliam as habilidades das pessoas com deficiência, a fim de prover uma vida independente e inclusiva.

Os produtos de tecnologia assistiva para pessoas com deficiência auditiva disponíveis no mercado apresentam algumas desvantagens. Sendo basicamente campainhas ou despertadores com alerta vibratório e luminoso, estes só serão eficazes se o usuário estiver próximo ao aparelho, não possuindo qualquer outro formato de conexão com o mesmo. Assim, pode-se dizer que as tecnologias referentes a pessoas com deficiência não atendem totalmente as suas necessidades.

Um ramo da área de engenharia de controle e automação que vem crescendo nos últimos tempos é a automação residencial, visto que é capaz de proporcionar condições de conforto, segurança e tranquilidade na própria casa do indivíduo. Muratori e Dal Bó (2011) define a automação residencial como "[...] um processo que, usando diferentes soluções e equipamentos, possibilita ao usuário usufruir o máximo de qualidade de vida na sua habitação". Um termo amplamente utilizado para automação residencial é a domótica. Muratori e Dal Bó (2014) explicam este termo como sendo a junção da palavra latina Domus (casa) com Robótica (controle automatizado).

Considerando que a automação facilita a vida de todas as pessoas, supõe-se que, a partir do seu uso, é possível proporcionar melhores condições de vida àquelas pessoas com algum tipo de deficiência ou mobilidade reduzida, surgindo assim o ramo da domótica assistiva. A domótica assistiva é um tipo de automação residencial que visa melhorar e facilitar a qualidade de vida das pessoas com deficiência em suas residências. Assim, pode-se considerar que esta ciência é a junção do conceito de tecnologia assistiva e automação residencial, com o intuito de trazer autonomia para as pessoas com deficiência, proporcionando-Ihes tranquilidade e comodidade em suas casas (BUNEMER et al., 2014).

Deficientes auditivos encontram dificuldades em atividades cotidianas domésticas, uma vez que não escutam a campainha, o interfone, o despertador ou qualquer outro alerta sonoro. França e Ono (2011) mostram sugestões de produtos que podem ser concebidos a fim de facilitar a comunicação com pessoas surdas, como através de uma campainha com um sinal luminoso ou vibratório e um despertador ou uma babá eletrônica com sinalizador vibratório.

De forma geral, há poucos estudos que abordam a questão da acessibilidade para os deficientes auditivos em edificações residenciais. Além disso, é reduzido o número de produtos disponíveis no 


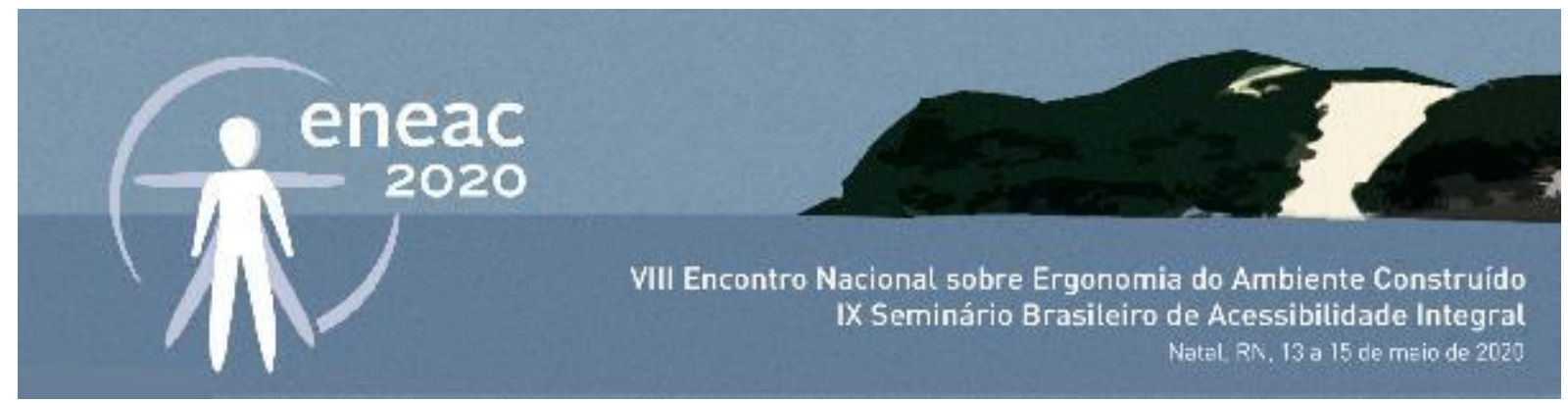

mercado para atender esse público alvo e, aqueles existentes, em sua maioria, possuem custo elevado. Sendo assim, o objetivo desta pesquisa foi desenvolver tecnologias assistivas de baixo custo para pessoas com deficiência auditiva. Estes dois produtos são uma campainha para acesso a residência e uma babá eletrônica. Ao final do desenvolvimento, os protótipos destes produtos foram testados e validados.

\section{METODOLOGIA}

Inicialmente, realizou-se uma pesquisa bibliográfica a respeito dos principais conceitos para desenvolver o estudo. Questões vinculadas a acessibilidade, deficiência auditiva e tecnologias assistivas foram pesquisadas no intuito de ampliar o conhecimento acerca do tema. Com base na revisão de literatura realizada, foi dado início ao desenvolvimento dos dois dispositivos eletrônicos propostos.

\subsection{Estrutura do sistema}

Para o presente trabalho foram projetados dois sistemas diferentes. O primeiro é uma campainha eletrônica, com um botão para simulação de um interruptor. O botão, por sua vez, é conectado a um microcontrolador Arduino. O microcontrolador é o dispositivo mais importante no sistema, por ser responsável pelo envio e recebimento de dados (BITTENCOURT, 2016).

O microcontrolador Arduino Uno foi escolhido por ser uma plataforma poderosa, de baixo custo e compatível com as necessidades do projeto (ARAÚjo et al., 2012). Para que ocorra o envio dos dados para o celular é necessário um módulo conectado ao Arduino, pois o Arduino não é totalmente responsável por enviar esses dados. E para essa função foi escolhido o Módulo GSM SIM 800L. A Figura 1 sintetiza as etapas do processo da campainha. O celular vibrará ao receber a mensagem, sinalizando que há alguém na porta de acesso.

Figura 1: Etapas do processo da campainha e babá eletrônica
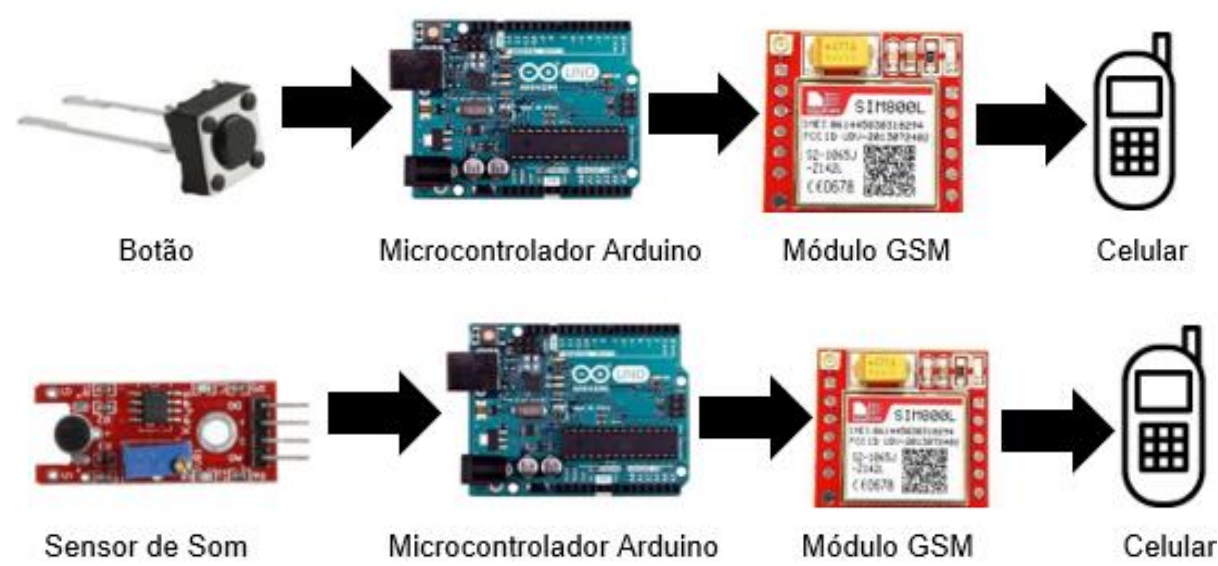

Fonte: Autores (2019). 


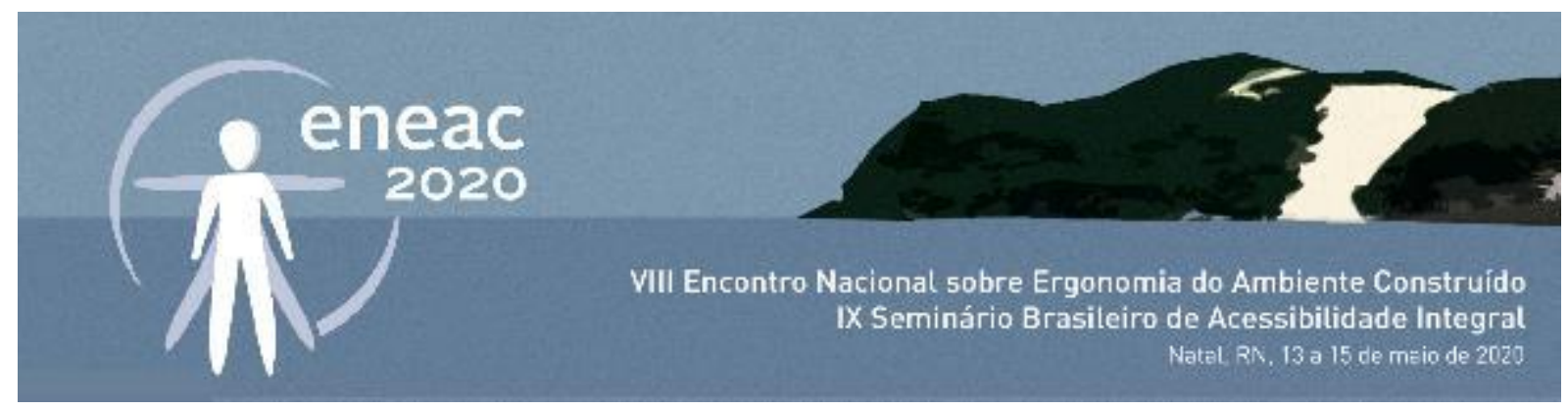

O segundo sistema é uma babá eletrônica, que usará um sensor de som KY-038 para captar os sons do bebê. O sensor foi escolhido por ser compatível com o Arduino, ter as características necessárias para o projeto e ser de baixo custo (BITTENCOURT, 2016). Quando o sensor captar o som do bebê, o microcontrolador Arduino enviará, a partir também de um Módulo GSM 800L, uma mensagem para o celular do usuário indicando captura sonora. O processo descrito está ilustrado na Figura 1.

\subsection{Fluxograma do processo}

Para uma melhor compreensão do processo como um todo, desenvolveram-se fluxogramas correspondentes aos algoritmos dos sistemas de campainha e babá eletrônica, respectivamente ilustrados na Figura 2. A partir deste fluxograma, é possível observar o processo realizado, desde a ativação do sinal até a transmissão de mensagens para a pessoa com deficiência auditiva. A principal diferença entre cada um dos sistemas se dá pela ativação do sinal: para a campainha, foi utilizado um botão convencional; já para a babá eletrônica, foi utilizado um sensor de som.

Figura 2: Fluxograma da campainha e babá eletrônica

\section{FLUXOGRAMA DA CAMPAINHA}

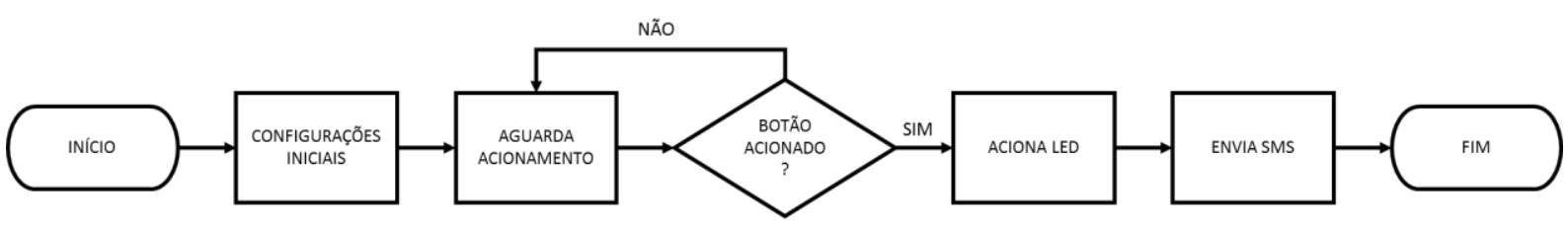

FLUXOGRAMA DA BABÁ ELETRÔNICA

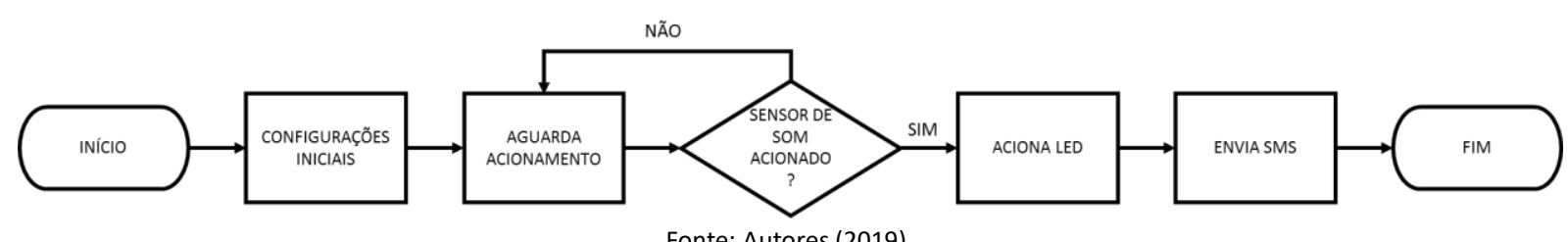

Fonte: Autores (2019).

\subsection{Simulação do protótipo em protoboard}

A protoboard, também conhecida como matriz de contatos, foi usada para os testes e montagem provisória dos protótipos. Estes são ideais para realização de testes, pois torna possível modificar os componentes eletrônicos de lugar a qualquer momento. Para Costa (2018), a protoboard é uma placa com orifícios conectados entre si, no sentido horizontal ou vertical, que garante a fácil montagem de circuitos elétricos experimentais. 


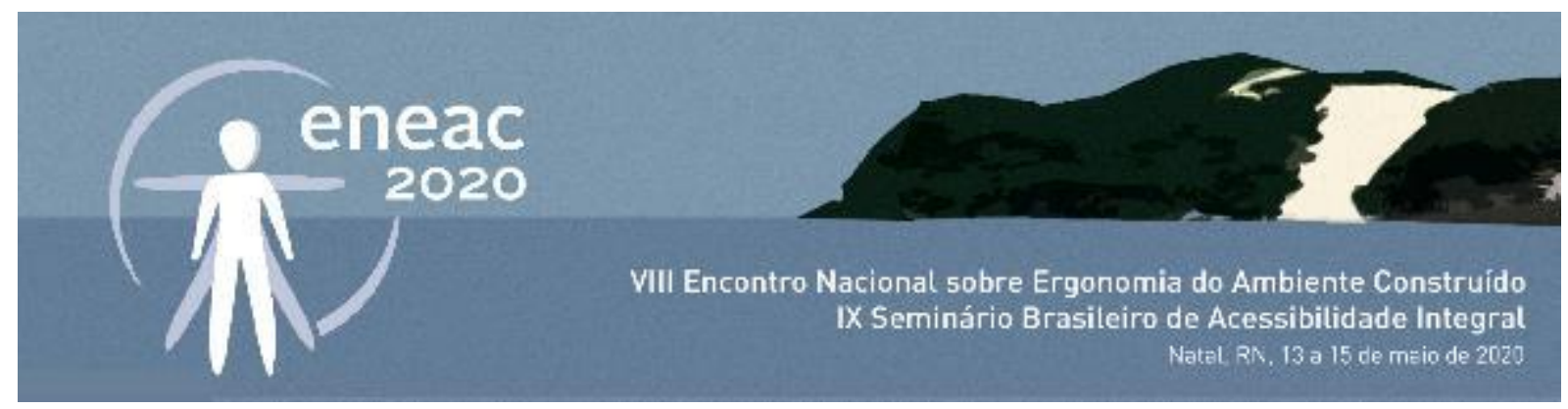

\section{RESULTADOS}

\subsection{Teste da campainha em protoboard}

O primeiro elemento a ser projetado foi a campainha eletrônica e suas conexões. Após, todos os componentes necessários para o desenvolvimento da campainha, todos foram alocados na protoboard.

O princípio de funcionamento da campainha é a geração de uma vibração, causada pelo recebimento de mensagens de texto, no celular do usuário. Estas mensagens tem por objetivo avisar o acionamento da campainha de sua casa. $O$ sistema testado em uma protoboard obteve resultados satisfatórios e foi possível entender o funcionamento de uma campainha real, dando base para as próximas etapas de desenvolvimento.

\subsection{Teste da babá eletrônica em protoboard}

Finalizados os primeiros testes da campainha, iniciou-se à segunda etapa de desenvolvimento: o estudo do funcionamento do sensor KY-038, utilizado para captar o som do choro de um bebê, trabalhando como uma babá eletrônica. Os testes físicos foram feitos diretamente na protoboard. Escolheu-se utilizar uma saída digital, pois além de ser mais simples a sua operação e leitura, a mesma é suficiente para realização do que foi proposto inicialmente nesse trabalho, de uma forma bem eficaz.

A lógica de programação dessa fase é semelhante à da primeira fase de testes. Entendeu-se que o funcionamento da campainha pode ser facilmente adaptado ao funcionamento da babá eletrônica, alterando o componente de "push button" pelo sensor de som.

Para uma operação mais eficaz, regulou-se o potenciômetro existente no sensor e, para isso, foram realizados testes reais utilizando o choro de um bebê, para que se alcançasse resultados realmente significativos. Assim sendo, a sensibilidade de captação de som do sensor ficou regulada para detectar o choro de um bebê, descartando outros possíveis ruídos dentro do ambiente.

\subsection{Protótipos finalizados}

A terceira etapa de desenvolvimento teve início após as implementações da campainha e do sensor de som serem feitas e seus resultados considerados como satisfatórios. Assim sendo, o próximo passo foi estudar o modo de operação do Módulo GSM SIM800L e, assim, conseguir realizar a conexão do módulo com os circuitos desenvolvidos nas etapas anteriores. A Figura 3 apresenta, respectivamente, o protótipo de campainha protótipo da babá eletrônica finalizado. 


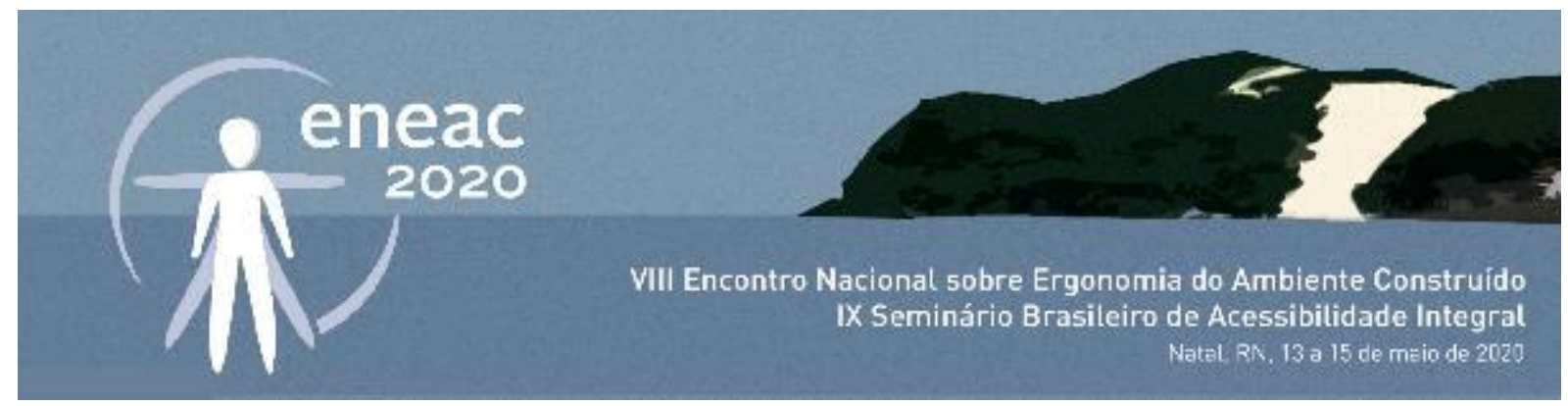

Figura 3: Protótipo da campainha e da babá eletrônica finalizados
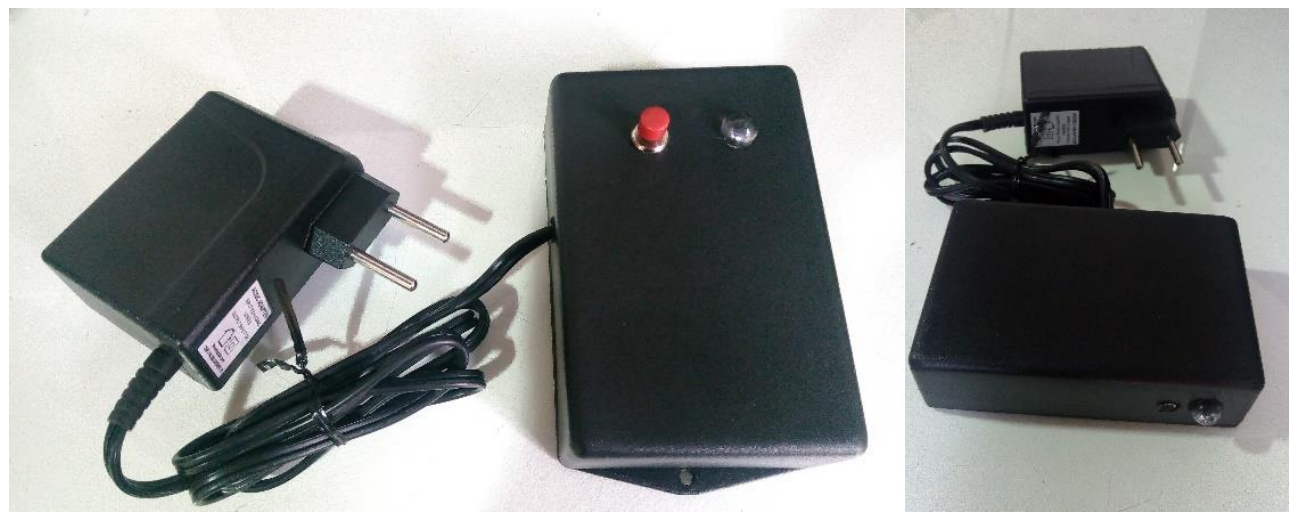

Fonte: Autores (2019).

Para que o usuário desse sistema seja avisado e consiga sentir as vibrações causadas pelo recebimento de mensagens, nos dois protótipos foram atribuídos o envio de quatro mensagens seguidas, com um espaço de tempo de cinco segundos entre o envio de cada mensagem de texto. Este tempo é necessário para que o comando seja enviado e a operadora consiga enviar as mensagens sem erro. Portanto, para uma maior eficiência, o celular vibrará quatro vezes para que a vibração não passe despercebida e o alerta seja recebido pelo usuário. Os resultados dos testes do envio de SMS, tanto para a campainha quanto para a babá eletrônica, podem ser vistos na Figura 4.

Figura 4: Resultado do teste da campainha e babá eletrônica

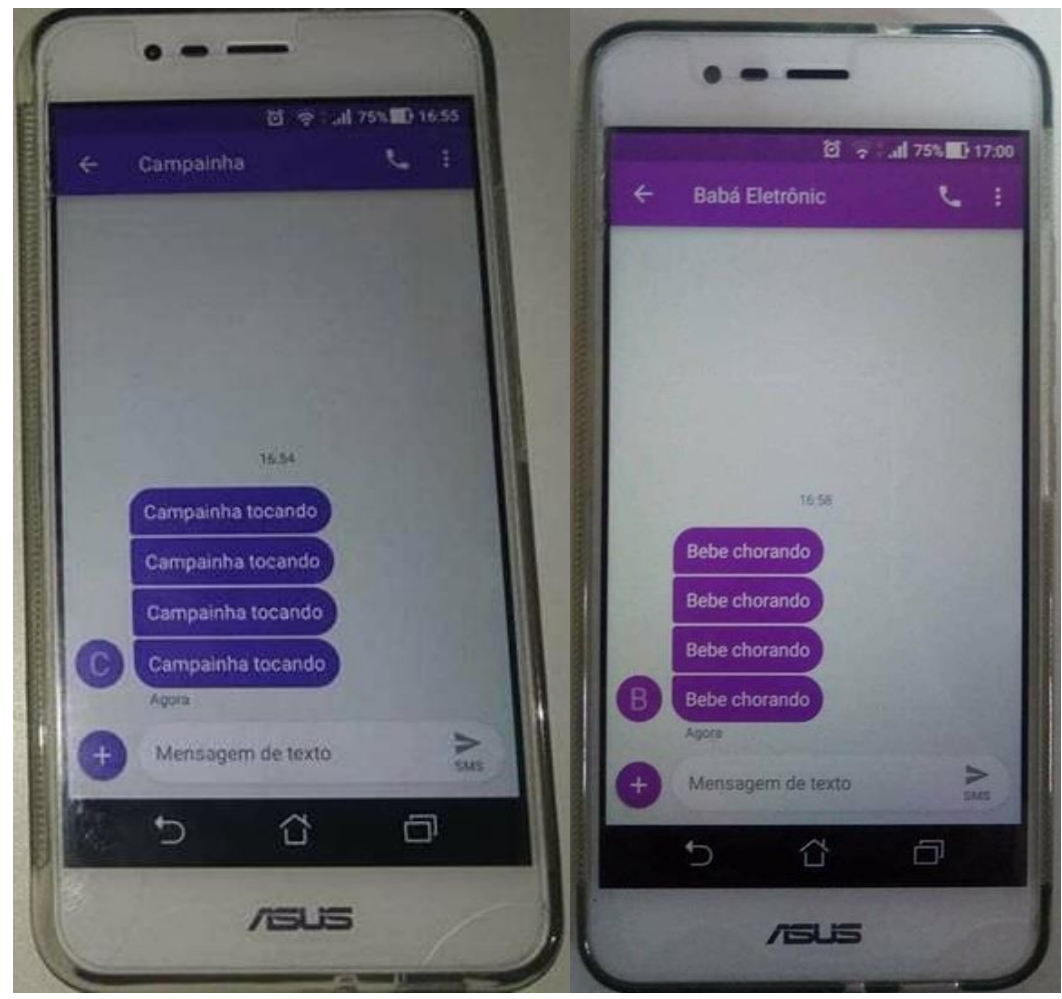

Fonte: Autores (2018). 


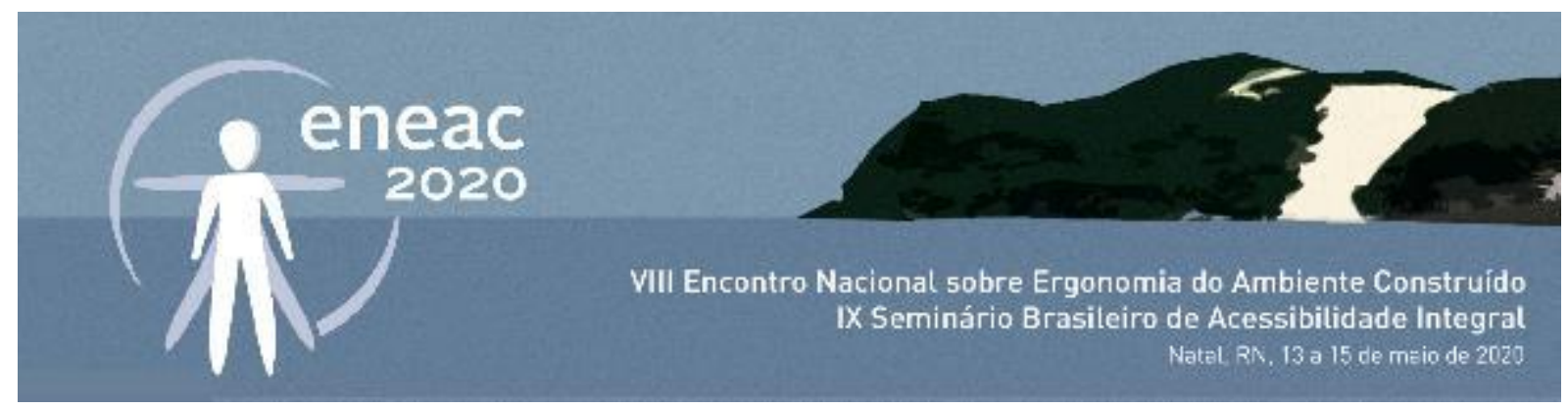

Dentro do código dos programas, pode-se inserir diversos números de celulares para receber o SMS e também é possível alterar o texto da mensagem a ser enviada. Para o SMS enviado pela campainha, o texto atribuído foi: "Campainha tocando" e para a babá eletrônica, o texto atribuído foi: "Bebê chorando", conforme observado nas imagens acima.

\section{CONCLUSÕES}

Tendo como objetivo o desenvolvimento de tecnologias assistivas de baixo custo para pessoas com deficiência auditiva, pode-se concluir que esta pesquisa obteve uma resposta positiva após a fase de prototipagem e validação. Ainda, constatou-se que existem pouquíssimos produtos já desenvolvidos no mercado, todos com custo alto, com a finalidade de facilitar a vida das pessoas com deficiência auditiva, sob o enfoque da automação residencial.

A pesquisa bibliográfica possibilitou entender quais as reais dificuldades encontradas pelos surdos em seu dia a dia. Foi possível identificar que a tecnologia está bastante presente no cotidiano das pessoas com deficiência auditiva. Dessa forma, pensou-se em uma solução de como a presença da tecnologia poderia atender, de um modo eficaz, algumas das dificuldades levantadas durante a pesquisa.

A campainha e a babá eletrônica são dispositivos amplamente utilizados e presentes nas residências em geral, com grande importância no dia a dia. Por isso, acredita-se que o acesso dos surdos a estas tecnologias assistivas trará grandes benefícios aos mesmos, tornando a vida das pessoas com deficiência mais acessível e, por consequência, inclusiva. Dessa forma, acredita-se que este projeto possibilitará a melhoria na qualidade de vida dos surdos a partir da disponibilização do acesso à tecnologia a partir de uma solução de baixo custo, fazendo com que suas vidas sejam mais autônomas e confortáveis.

\section{REFERÊNCIAS}

ANDRADE, I. F. Sistema informacional para a orientação espacial em terminais aeroportuários a partir das estratégias adotadas pelos indivíduos. 2016. 378 f. Tese (Doutorado) - Curso de Arquitetura e Urbanismo, Centro Tecnológico, Universidade Federal de Santa Catarina, Florianópolis, 2016.

ARAÚJO, I. B. Q., SOUTO, F. V., COSTA JÚNIOR, A. G., SOUZA, C. P. Desenvolvimento de um protótipo de automação predial/residencial utilizando a plataforma de prototipagem eletrônica Arduino. In: Anais: XL Congresso Brasileiro de Educação em Engenharia (COBENGE), Belém, UFPA. 2012.

BERSCH, R. Introdução à Tecnologia Assistiva. 2013. Disponível em: <http://www.assistiva.com.br/>. Acesso em: 22 nov. 2018.

BITTENCOURT, Z., CHERAID, D. C., MONTILHA, R. C. I., GASPARETTO, M. E. R. F. Expectativas quanto ao uso de tecnologia assistiva. Journal of Research in Special Educational Needs, v. 16, n. S1, p. 492-496, 2016.

BRASIL. Decreto no 5.296 de 2 de dezembro de 2004. Regulamenta as Leis nos 10.048, de 8 de novembro de 2000, que dá prioridade de atendimento às pessoas que especifica, e 10.098, de 19 de dezembro de 2000, que estabelece normas gerais e critérios básicos para a promoção da acessibilidade das pessoas portadoras de deficiência ou com mobilidade reduzida, e dá outras providências. 2004.

BRASIL. Lei no 10.436, de 24 de abril de 2002. Dispõe sobre a Língua Brasileira de Sinais e dá outras providências. Diário Oficial da União, Brasília, 25 de abril de 2002. 


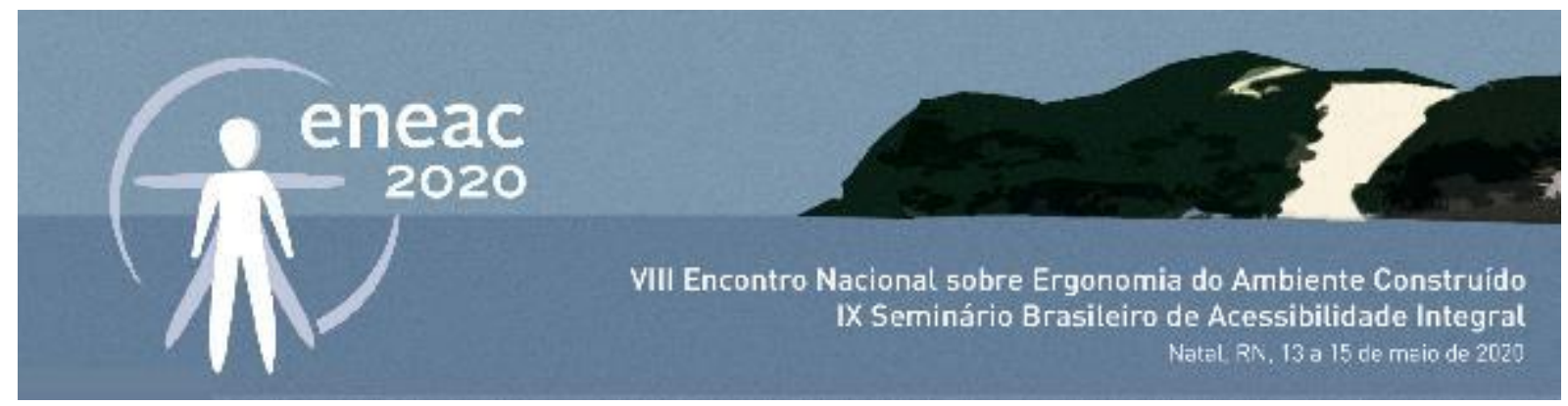

BUNEMER, Ricardo. Domótica Assistiva Utilizando Sistemas Integrados de Supervisão e Controle. 2014. $146 \mathrm{f}$. Dissertação (Mestrado) - Curso de Engenharia Mecânica, Departamento de Projeto Mecânico, Universidade Estadual de Campinas, Campinas, 2014.

CASTRO, S. S., LEFEVRE, F., LEFEVRE, A. M. C., CESAR, C. L. G. Acessibilidade aos serviços de saúde por pessoas com deficiência. Rev. Saúde Pública [online], vol.45, n.1, pp.99-105, 2011.

COSTA, J. R. Aulas práticas realizadas na protoboard sob suporte de simulações criadas no modellus. $2018.122 \mathrm{f}$. Dissertação (Mestrado em Ensino de Física) - Programa de Pós-Graduação do Instituto Federal de Educação, Ciência e Tecnologia do Ceará, Sobral, CE, 2018.

DISCHINGER, M., BINS ELY, V. H. M., PIARDI, S. M. D. G. Promovendo acessibilidade espacial nos edifícios públicos: Programa de Acessibilidade às Pessoas com Deficiência ou Mobilidade Reduzida nas Edificações de Uso Público. Florianópolis: MPSC, 2012.

FRANÇA, A. C. C. V.; ONO, M. M. Deaf people's social interaction in daily life mediated by communication product and service systems. Cadernos Gestão Pública e Cidadania, São Paulo, v. 16, n. 59, Jul./Dez. 2011.

IBGE. Censo demográfico 2010: características gerais da população, religião e pessoas com deficiência. Ministério do Planejamento, Orçamento e Gestão. Rio de Janeiro: Instituto Brasileiro de Geografia e Estatística, 2012. 215 p.

LOPEZ, M., HAMMES, G., VERGARA, L.. Desenvolvimento de Produtos Para A Diversidade Humana: Ouvindo A Pessoa Surda (AC). Blucher Design Proceedings, v. 2, n. 4, p. 262-278, 2016.

MONTEIRO, M. S. História dos movimentos dos surdos e o reconhecimento da Libras no Brasil. In: ETD - Educação Temática Digital, vol. 7, n. 2, p. 295-305, 2006.

MOORES, D. Educating the deaf, psychology, principles and practice. Boston: Houghton Mifflin Co. 1978.

MURATORI, J. R., DAL BÓ, P. H. Automação Residencial conceitos e aplicações. 2.ed. Belo Horizonte: Edurece, 2014.

MURATORI, J. R., DAL BÓ, P. H. Capítulo I Automação residencial: histórico, definições e conceitos. O setor elétrico, p. 70, 2011. 